\title{
Principales problemas económicos y sociales heredados del impacto de la crisis económica en el mercado de trabajo
}

\author{
Luis Sanzo González \\ Departamento de Empleo y Políticas Sociales, Gobierno Vasco \\ <SanzoGLu@euskadi.eus>
}

\begin{abstract}
Artikulu honetan proposatzen da krisialdi ekonomikoak Euskadiko laneko merkatuan utzi dituen -eta oraindik ere uzten dituen- ondorioak aztertzea. 2007 eta 2013/2014 urteetako laneko okupazio eta langabeziaren azterketaren bidez, batetik, azterlanak identifikatzen ditu produktiboak diren sektoreak eta hondamendi ekonomikoak gehien kalteturiko talde sozialak; eta, bestetik, nabarmentzen dira gaur egungo egoeratik desberdintzen diren ezaugarri batzuek beste autonomia-erkidego batzuetan, eta baita ere hirurogeita hamarreko eta laurogeiko hamarkadaren hasieran Europan bizi izandako industriaren birmoldatzearen prozesuak izandako eraginak. Azkenik, bertan burutzen dira gogoeta batzuek azken aldiko eboluzioaz eta etorkizuneko joeretan euskal eredu sozioekonomikoaren iraunkortasunerako ezinbestekotzat hartzen diren ondorengo bi alderdi hauetaz: beregain lan egiten duen biztanleria eta sektore publikoa.
\end{abstract}

\section{GAKO-HITZAK:}

Krisialdi ekonomikoa, laneko merkatua, langabezia, eragin soziala, eboluzioa, ikuspegiak.
Este artículo se propone analizar las consecuencias que la crisis económica ha dejado -y sigue dejandoen el mercado de trabajo de Euskadi. El examen de los cambios en la ocupación y el desempleo entre 2007 y 2013/2014 permite al estudio, por un lado, identificar los sectores productivos y los grupos sociales más perjudicados por la debacle económica y, por otro, señalar algunas características que distinguen la actual situación de la existente hoy día en otras comunidades autónomas, o incluso del proceso de reconversión industrial vivida en Europa entre finales de la década de los setenta y principios de los ochenta del siglo pasado. Finalmente, se plantean algunas reflexiones sobre la evolución reciente y la tendencia futura de dos factores considerados clave para la sostenibilidad del modelo socioeconómico vasco: la población que trabaja por cuenta propia y el sector público.

\section{Palabras Clave:}

Crisis económica, mercado de trabajo, desempleo, impacto social, evolución, perspectivas. 


\section{El desigual impacto sectorial de la crisis y el papel determinante de la crisis industrial}

Los datos del Censo del Mercado de Trabajo permiten realizar un seguimiento detallado del impacto de la crisis del periodo 2007-2013 en la evolución de la ocupación en la Comunidad Autónoma de Euskadi (CAE). En ese periodo, 84.701 personas pierden su empleo en la CAE, un $8,7 \%$ de la población ocupada en 2007.

Un primer aspecto que destacar es el impacto completamente desigual de la evolución de la ocupación sectorial en Euskadi (Gráficos 1 y 2). El dato más relevante es que la crisis ocupacional se concentra, en lo fundamental, en una serie de sectores y ramas recesivas durante el conjunto del periodo. De esta forma, la industria, la construcción y las ramas de transportes y comunicaciones constituyen el verdadero núcleo de la crisis, con una pérdida de 112.201 ocupaciones entre 2007 y 2013. La caída del empleo en los sectores y ramas señalados no tiene comparación con las 8.325 ocupaciones perdidas en las ramas de comercio, instituciones financieras y administración pública. Entre 2007 y 2013 aumenta incluso la ocupación en el resto de las ramas de la economía vasca, en particular en los servicios a las empresas y en los grandes servicios a la población (educación, sanidad y servicios sociales).
En este contexto, resulta de particular importancia la pérdida de ocupación en el sector industrial. En términos relativos, la caída más importante afecta a la construcción, un sector en el que se reduce en un 40,9\% la población ocupada entre 2007 y 2013 (Gráfico 2). La reducción de ocupación es también algo más elevada en el sector de transportes y comunicaciones, con una pérdida del $26,9 \%$ de las ocupaciones.

Sin embargo, la pérdida del $22,9 \%$ de la ocupación en la industria entre 2007 y 2013 es más determinante en términos cuantitativos (Gráfico 3). Dentro de los sectores y ramas regresivos en ese periodo, un $49,1 \%$ de la reducción total de población ocupada se vincula, de hecho, a la industria; un 30,1\%, a la construcción; y 13,8\%, a las ramas de transportes y comunicaciones. En conjunto, estos tres ámbitos de actividad económica recogen un $93 \%$ de la caída de la ocupación.

Incluso en términos relativos, la crisis industrial resulta, en realidad, mayor que en cualquier otra rama o sector, tal y como refleja el impacto de la caída ocupacional de 2007-2013 sobre las ganancias de ocupación del periodo 1997-2007 (Gráfico 4). En la industria, la crisis del periodo 2007-2013 supone una pérdida de 1,70 ocupaciones por cada ocupación ganada entre 1997 y 2007 , superando la cifra de 1,34 de la construcción, el segundo sector en el que se pierde durante la crisis más ocupación que la ganada entre 1997 y 2007.

Gráfico 1. Evolución de la ocupación, por sectores y ramas de actividad. CAE, 2007-2013

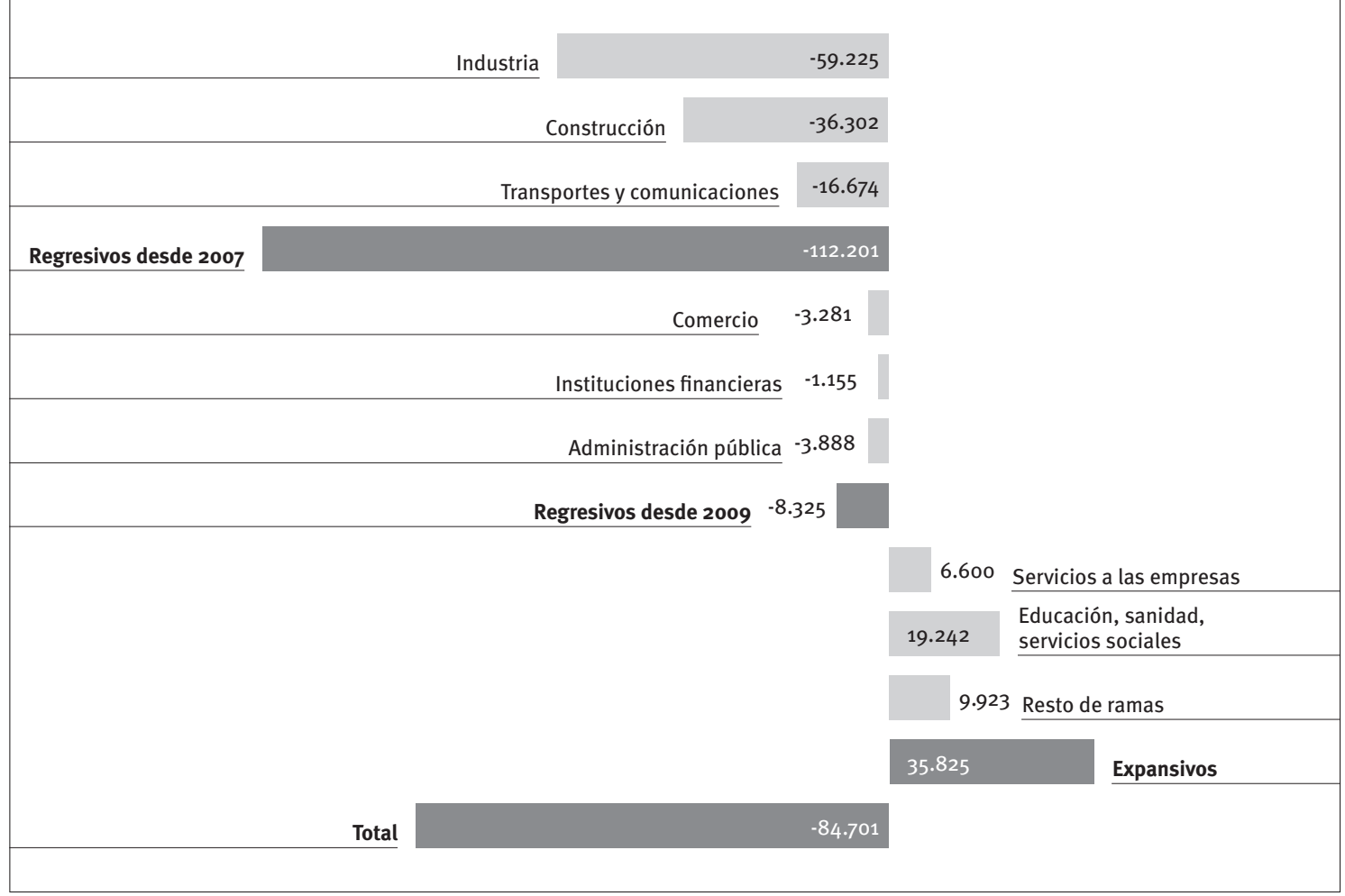

Fuente: Censo del Mercado de Trabajo (Órgano Estadístico del Departamento de Empleo y Políticas Sociales del Gobierno Vasco). 


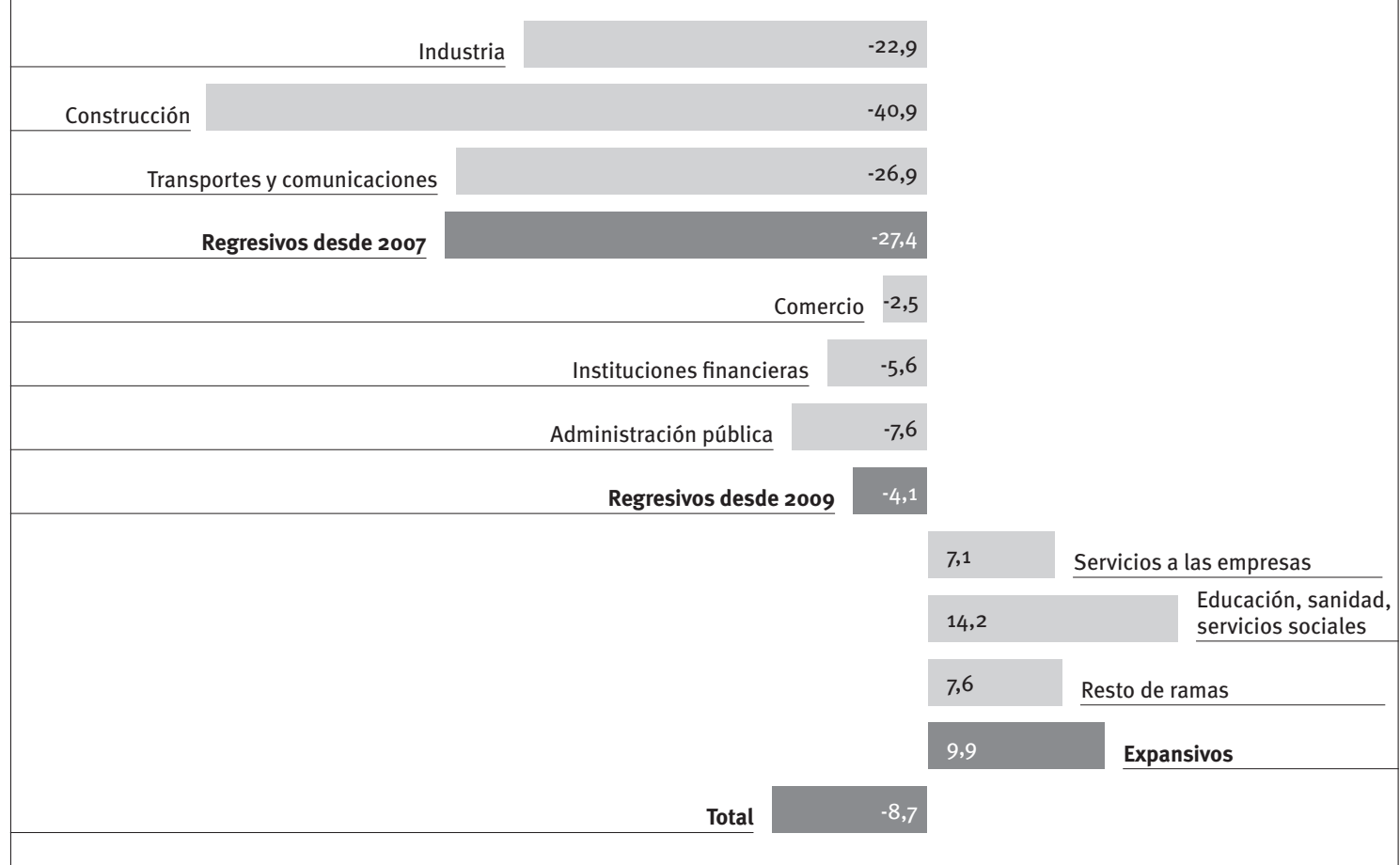

Fuente: Censo del Mercado de Trabajo (Órgano Estadístico del Departamento de Empleo y Políticas Sociales del Gobierno Vasco).

Gráfico 3. Distribución de las 120.526 ocupaciones perdidas en sectores y ramas regresivos. CAE, 2007-2013 (\%)

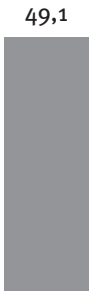

Industria

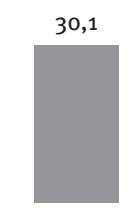

Construcción

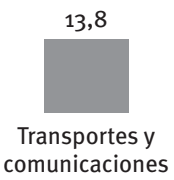

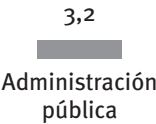

Fuente: Censo del Mercado de Trabajo (Órgano Estadístico del Departamento de Empleo y Políticas Sociales del Gobierno Vasco).

Gráfico 4. Impacto de la caída del periodo 2007-2013 sobre las ganancias de ocupación del periodo 1997-2007 en los principales sectores y ramas regresivos*. CAE (en \%)

Industria

Construcción

Transportes y comunicaciones

Administración pública

Comercio

\section{0,3}

\section{4,3}

89,7

27,8

* Caída 2007-2013 / ganancias 1997-2007 * 100.

Fuente: Censo del Mercado de Trabajo (Órgano Estadístico del Departamento de Empleo y Políticas Sociales del Gobierno Vasco). 
En todo caso, resulta necesario analizar los fundamentos sobre los que sería posible recuperar el empleo en los sectores y ramas de la economía vasca más afectados por la crisis: industria, construcción, y transportes y comunicaciones. Como consecuencia de la crisis, en este ámbito de la economía vasca la ocupación a finales de 2013 era menor a la existente en 1993 (Gráfico 5).

Una de las claves para la recuperación se relaciona con la posibilidad de reeditar el éxito que supuso, tras el declive del periodo de la reconversión, la creación de nuevo empleo industrial en Euskadi a lo largo de los años noventa y hasta 2002. A fin de buscar las vías para superar este reto, resulta, sin embargo, importante tener en cuenta dos hechos. Por una parte, es preciso tomar conciencia de que los límites al avance de la ocupación industrial se alcanzan con mucha anterioridad a la crisis financiera de 2008. En Euskadi, como en otros lugares, la crisis de ocupación se adelanta en muchas ramas de este sector al periodo 2005-2007, en muchos casos después de un tiempo de estancamiento ocupacional iniciado en 200202003.

Por otra parte, es necesario considerar que, en la industria, el impacto cuantitativo y relativo de la reciente caída de ocupación en el periodo 2006-2012 ha sido tan fuerte o mayor en Europa que durante el proceso de reconversión industrial de finales de los años setenta y primeros ochenta (Gráficos 6 y 7). La única excepción a esta realidad es la experiencia de Alemania, uno de los pocos países europeos que consiguen, junto con algunos de su entorno, no caer en el declive y mantener el empleo industrial.

Gráfico 5. Evolución de la ocupación en los sectores primario y secundario, transportes y comunicaciones. CAE, 1993-2014 (miles de personas)

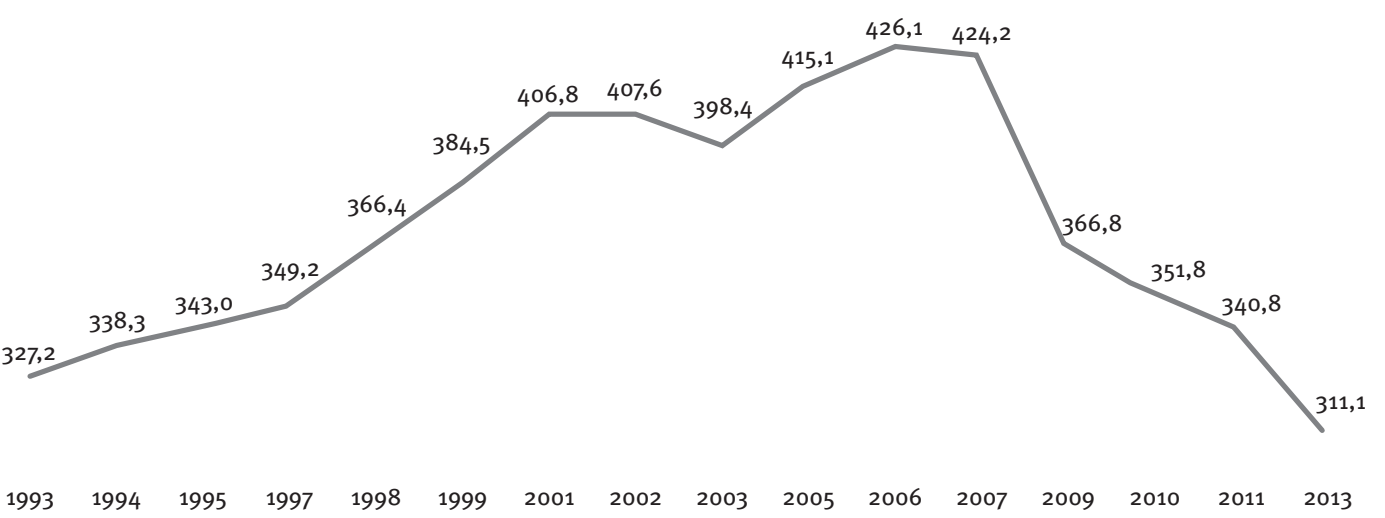

Fuente: Censo del Mercado de Trabajo (Órgano Estadístico del Departamento de Empleo y Políticas Sociales del Gobierno Vasco).

Gráfico 6. Comparación de la intensidad y ritmo de caída de la ocupación en la industria manufacturera en dos periodos de crisis industrial. Alemania, Benelux - Reino Unido - Francia - Italia - Reino Unido, y España, 1997-1983 y 2006-2012 (\% respecto al primer año de cada periodo)

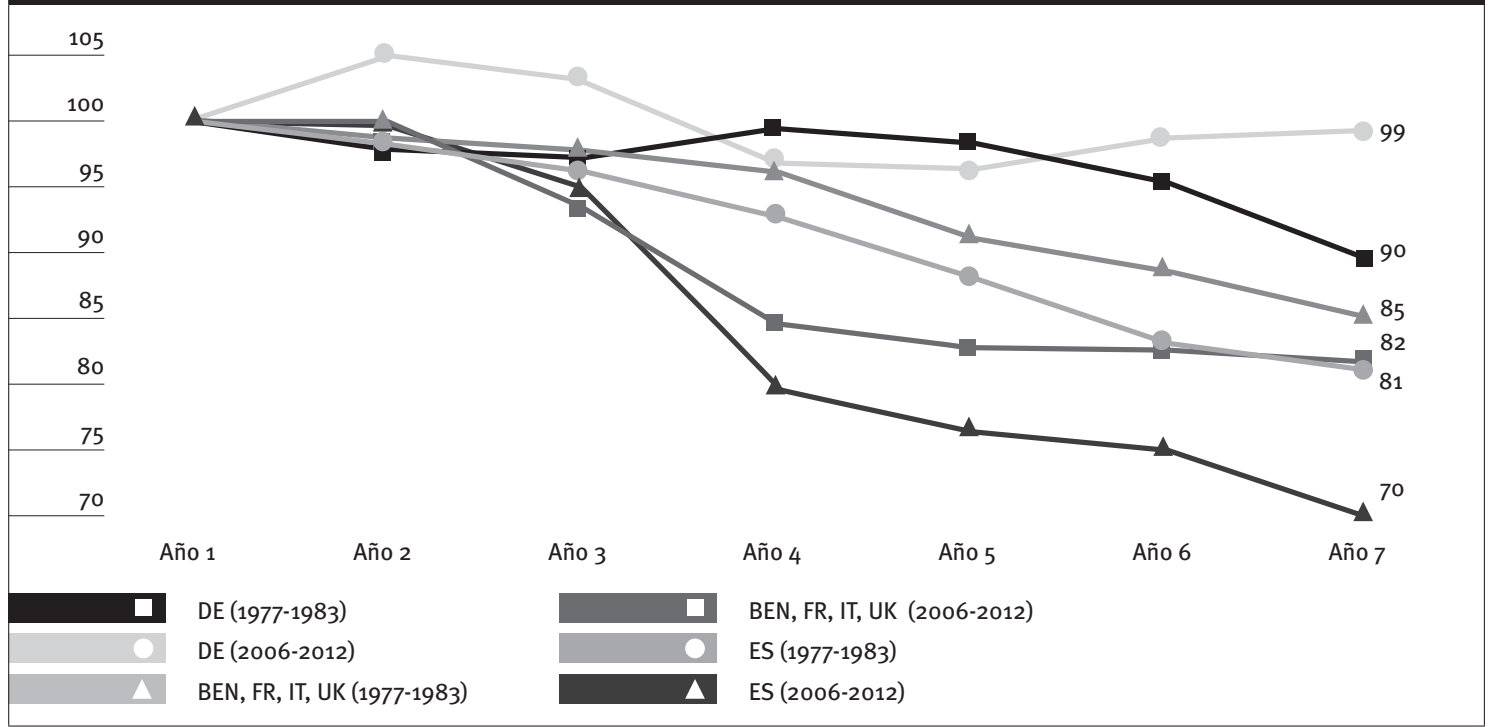

Fuente: Elaboración propia partir de datos de Eurostat, Labour Force Survey (Office for National Statistics) y OCDE. 


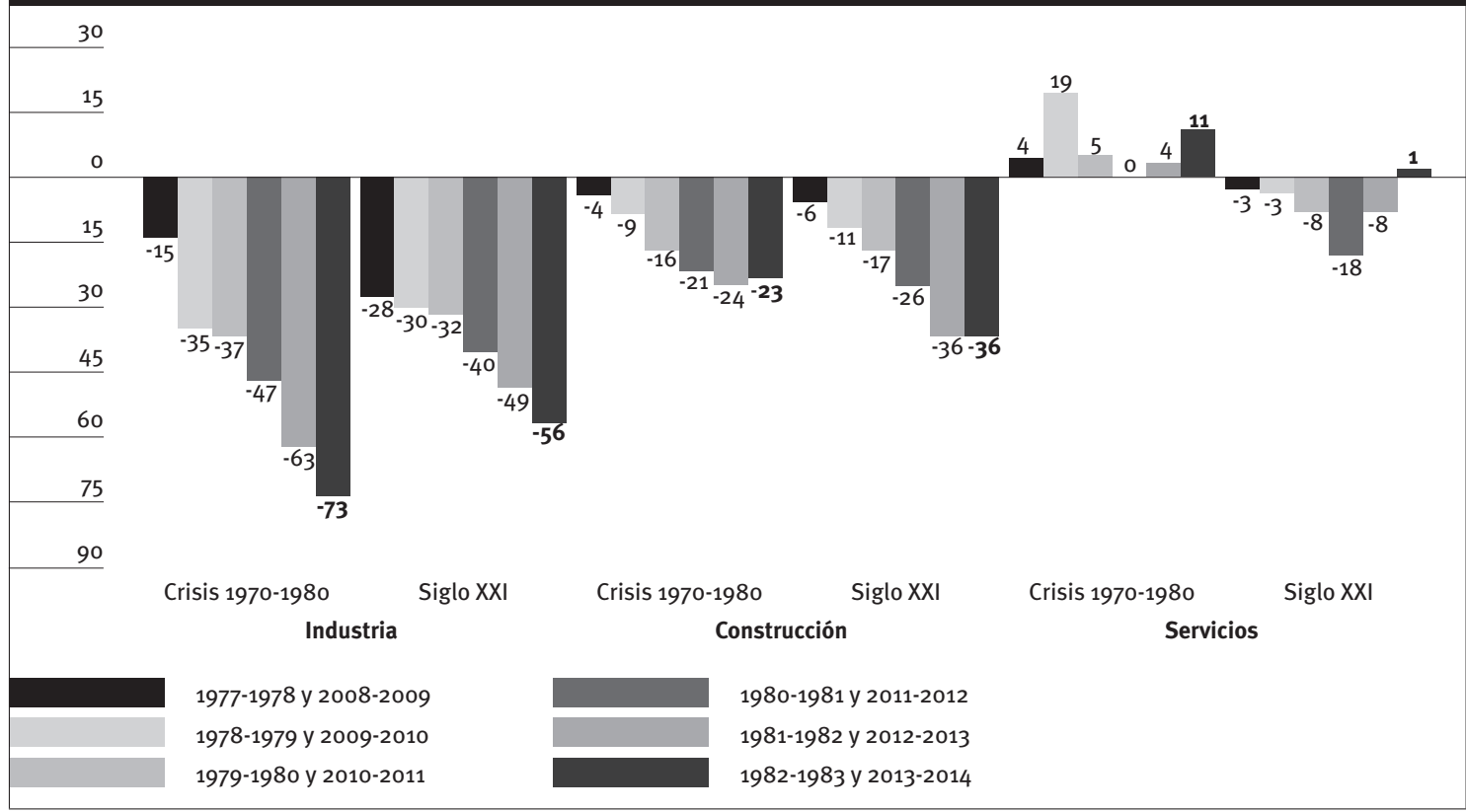

Fuente: Elaboración propia a partir de datos de la Encuesta de Población Activa (INE).

\section{Los colectivos afectados por la crisis de la ocupación}

El estudio de la dinámica sectorial de la ocupación es relevante en sí mismo, pero también tiene sentido por sus fuertes implicaciones sociales, ya que afecta a la población trabajadora que se ha visto más perjudicada por la crisis. Los datos muestran, en este sentido, que el colectivo afectado ha sido bastante específico, y que no ha habido una distribución más o menos equilibrada de las pérdidas ocupacionales por grupos o categorías sociales o económicas.

\subsection{La población obrera del sector privado y la población asalariada en los escalones bajos de la escala laboral}

La caída del empleo en la industria, la construcción y las ramas de transportes y comunicaciones se ha traducido en un fuerte descenso de la ocupación en las profesiones obreras (Gráfico 8). Después de aumentar -de forma prácticamente continuada- de 296.400 personas ocupadas en 1993 a 454.600 en 2007 , la crisis se manifiesta en una caída de casi 100.000 ocupaciones en 2013 en este tipo de profesiones. Las 358.200 personas ocupadas de 2013 devuelven la ocupación a los niveles existentes entre 1997 y 1998.

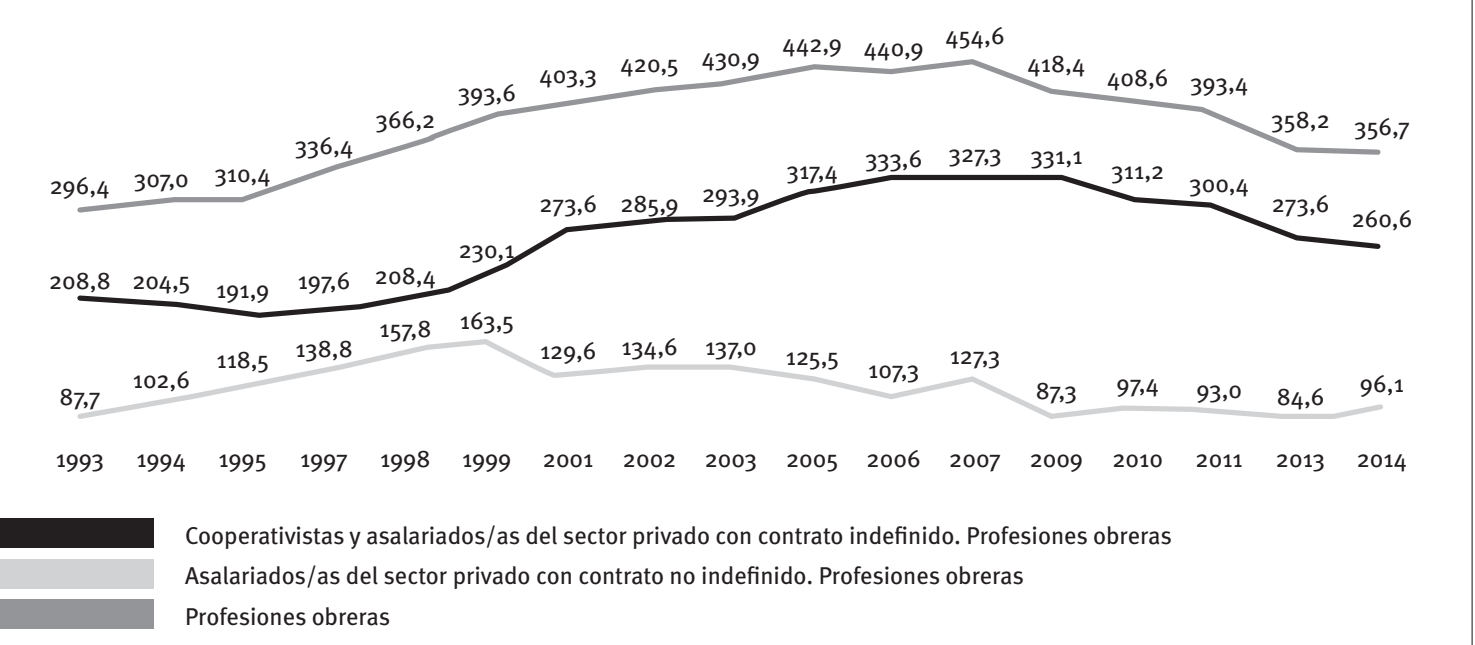

Fuente: Censo del Mercado de Trabajo (Órgano Estadístico del Departamento de Empleo y Políticas Sociales del Gobierno Vasco). 


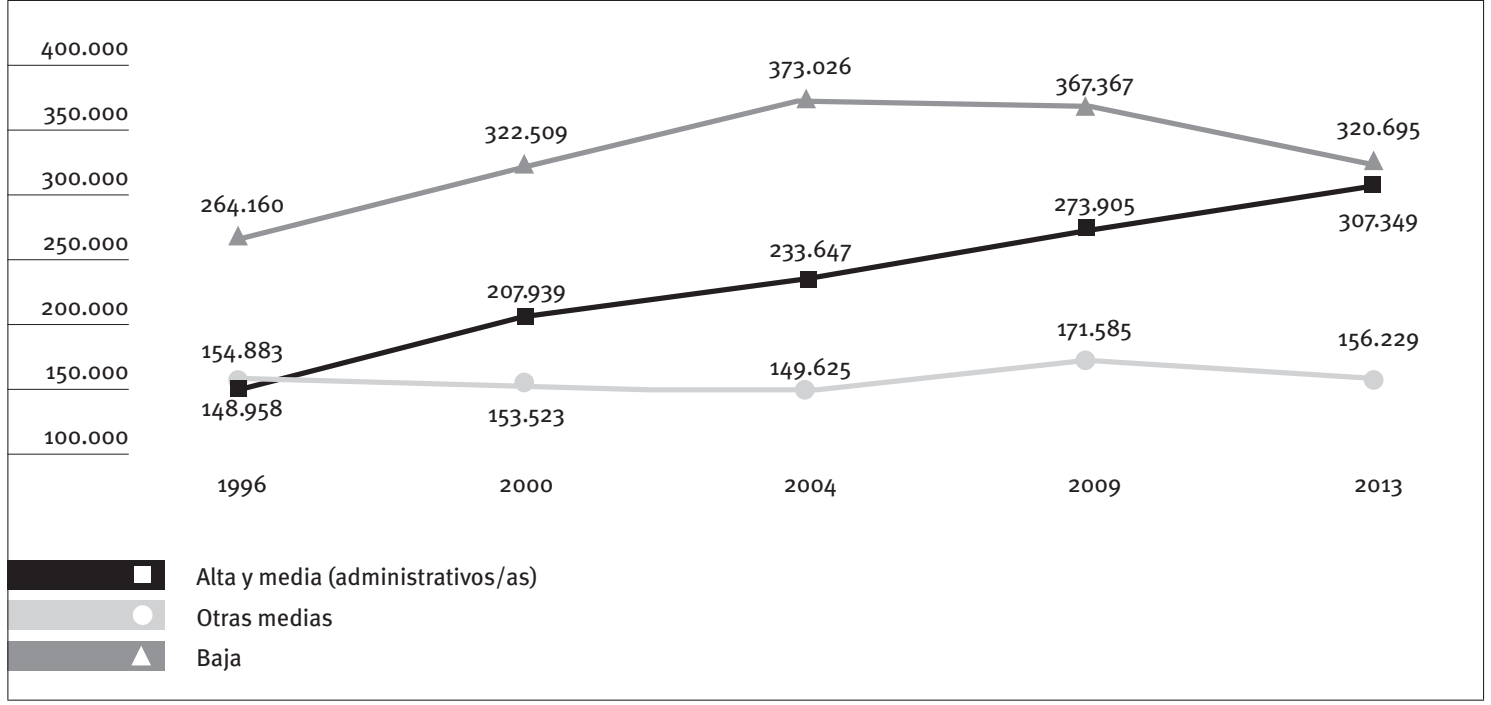

Fuente: Encuesta de Condiciones de Trabajo (Órgano Estadístico del Departamento de Empleo y Políticas Sociales del Gobierno Vasco).

A partir de 2009, el proceso de reducción de la ocupación en profesiones obreras, que hasta entonces había afectado a personas con contrato temporal, se extiende además a aquéllas con relación previamente estable con la empresa. La población obrera con contrato indefinido cae, así, de 331.100 personas en 2009 a 273.600 en 2013.

Sin embargo, el principal cambio en la ocupación asalariada durante el periodo de crisis se relaciona con su dinámica completamente diferenciada según la categoría profesional (Gráfico 9). En este sentido, los datos de la Encuesta de Condiciones de Trabajo revelan que uno de los fenómenos más llamativos del periodo 2009-2013 es el desplazamiento relativo hacia arriba de la estructura de categorías del sistema de empleo asalariado de la CAE. Se trata de la consecuencia de un cambio estructural a largo plazo, definido ante todo por el incremento del peso relativo en el sistema de empleo asalariado de la población trabajadora de categoría alta o con una categoría media vinculada a oficialías administrativas. Este colectivo de población ocupada ha aumentado de forma continuada desde las 148.958 personas de 1996 a las 307.349 de 2013, pasando de representar un $26,2 \%$ de la población asalariada y asimilada a mediados de los años noventa al 39,2\% de 2013.

Después de incrementarse de las 419.042 personas en 1996 a las 538.952 en 2009, la crisis incide claramente en el resto de la población ocupada, reduciéndose a 476.925 personas en 2013 , una cifra similar a las 476.032 ocupaciones de 2000. Sin embargo, el principal impacto de la crisis ocupacional se centra en las categorías profesionales bajas. En este grupo, cuya ocupación había aumentado de 264.160 a 373.036 personas entre 1996 y 2004 , la crisis se traduce inicialmente en una cierta estabilización a la baja, con 367.367 personas ocupadas en 2009. Sin embargo, la extensión de la crisis acaba por situar en apenas 320.695 personas el nivel de empleo de 2013.
Esta caída de 52.331 personas supone una disminución del 14,0\% en las cifras de 2004, quedando la ocupación de este grupo también por debajo de las cifras de 2000. En términos ocupacionales, por tanto, la crisis se centra, ante todo, en la población situada en la parte más baja de la escala laboral.

\subsection{Las personas jóvenes}

A pesar de que los cambios demográficos no han hecho sino reducir a la baja la población de 16 a 29 años, este grupo etario es el principal afectado por la caída de la ocupación asociada a la crisis (Gráfico 10). Entre 2009 y 2013 , periodo central de la reducción de empleo, un $84,9 \%$ de ésta se concentra en las personas de ese grupo de edad.

\subsection{Los hombres}

La concentración de la caída de la ocupación en la industria, la construcción y las ramas de transportes y comunicaciones determina una evolución muy diferente de la ocupación masculina y femenina:

- En el caso de la población femenina (Gráfico 11), la reducción de la ocupación caracteriza el periodo 2010-2013, pero resulta moderada, manteniéndose la ocupación de 2013 por encima de la existente en 2007. En comparación con 1997, además, hay un $52,7 \%$ más de mujeres ocupadas en 2013, cuando concluye en lo fundamental la crisis económica.

- En fuerte contraste, la ocupación masculina de 2013 se reduce de 565.800 personas a 476.300 en 2013 (Gráfico 12). Este descenso de 89.500 personas sitúa la ocupación masculina de 2013 en cifras inferiores a las de 1997, con 482.200 hombres ocupados en aquel momento. 
Gráfico 10. Distribución de la caída de la ocupación entre la población asalariada y asimilada, por sexo y edad.

CAE, 2009-2013 (\%)

\begin{tabular}{|r|}
\hline 60 \\
\hline 50 \\
\hline 40 \\
\hline 30 \\
\hline 20 \\
\hline 10 \\
\hline 0 \\
\hline
\end{tabular}

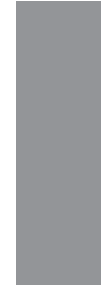

Hombres,

16-29 años

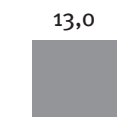

0,0

Hombres, Hombres,

30-44 años

45-64 años
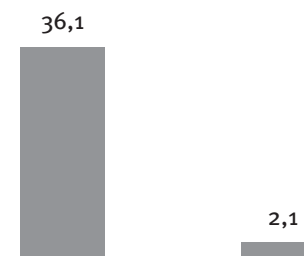

0,0

Mujeres,

16-29 años

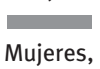

Mujeres,
30-44 años

Mujeres, 45-64 años

Fuente: Encuesta de Condiciones de Trabajo (Órgano Estadístico del Departamento de Empleo y Políticas Sociales del Gobierno Vasco).

Gráfico 11. Evolución de la población femenina activa, ocupada y parada de 16 a 64 años. CAE, 1993-2014 (miles de personas)

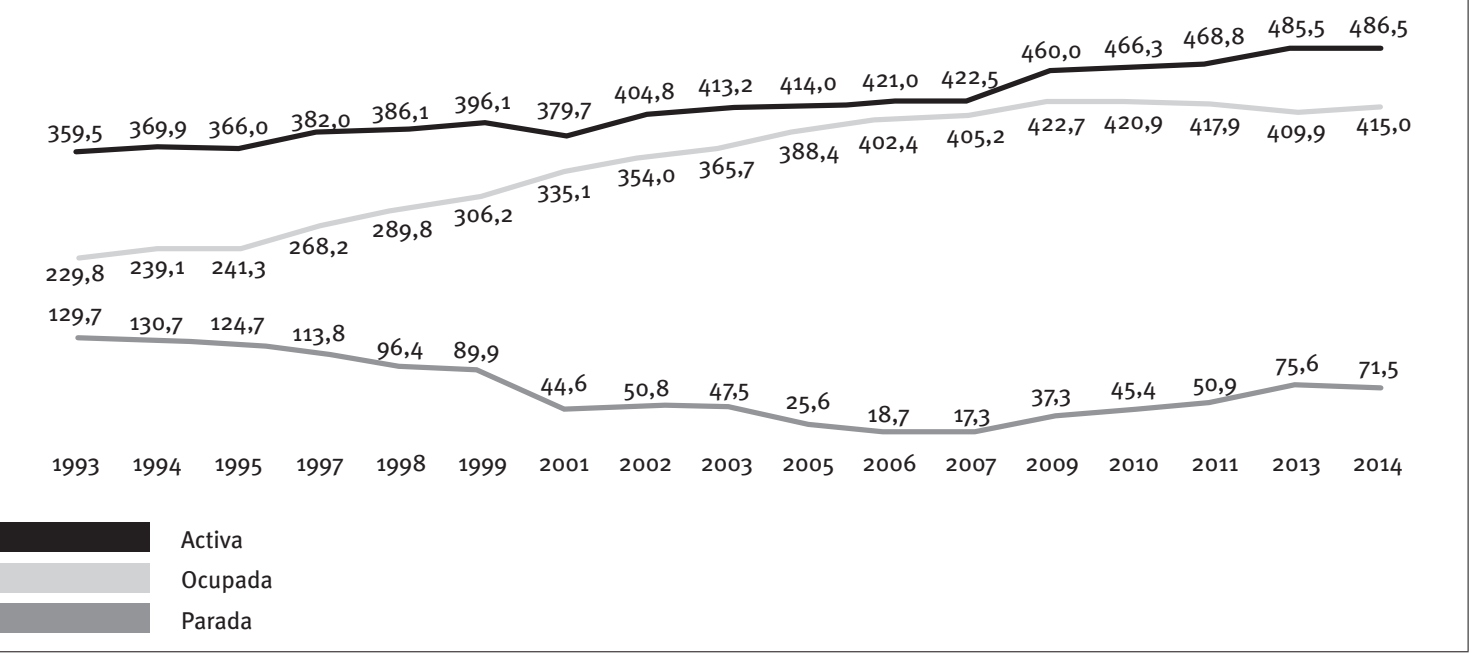

Fuente: Censo del Mercado de Trabajo (Órgano Estadístico del Departamento de Empleo y Políticas Sociales del Gobierno Vasco).

Gráfico 12. Evolución de la población masculina activa, ocupada y parada de 16 a 64 años. CAE, 1993-2014 (miles de personas)
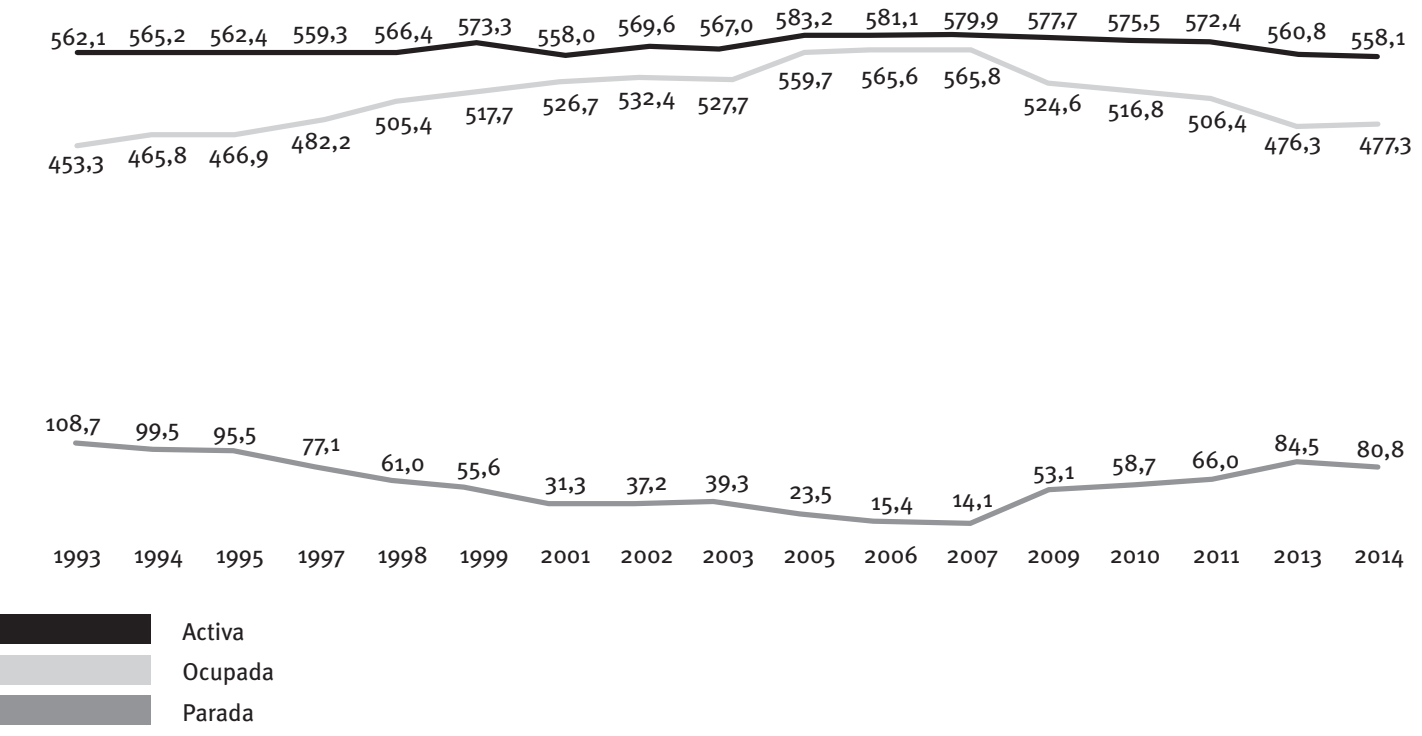

Fuente: Censo del Mercado de Trabajo (Órgano Estadístico del Departamento de Empleo y Políticas Sociales del Gobierno Vasco). 


\section{El impacto social de la crisis}

Durante la crisis, Euskadi ha sido capaz de mantener unas tasas de desempleo claramente inferiores tanto a las de España como a las que caracterizaban a la CAE en anteriores crisis (Gráfico 13). En este sentido, Euskadi es la única comunidad autónoma en la que la tasa media de paro durante el periodo central de la crisis actual resulta claramente inferior a la del periodo $1992-1997$ (13,9\% frente a $21,9 \%)$.

Sin embargo, el impacto social de la crisis actual es muy superior a lo que reflejan las cifras anteriores, por una serie de razones que se mencionan a continuación.

\subsection{El impacto del desempleo en personas con responsabilidades familiares}

En primer lugar, se observan cambios sustanciales en el tipo de personas afectadas por el desempleo en la actualidad. Por una parte, se reduce de forma sustancial el peso del desempleo juvenil dentro del desempleo total en periodos de crisis (Gráfico 14). Al final de la crisis vinculada al proceso de reconversión industrial, en 1986 , un 49,5\% de las personas desempleadas tenían entre 16 y 24 años. Esta proporción ya cayó al $28,3 \%$ en 1996, al final de la crisis de primeros de los años noventa. En 2013, apenas un $12 \%$ de las personas desempleadas tienen menos de 25 años. En cambio, la proporción de personas de 450 más años en la población parada aumenta del $10 \%$ y el $15 \%$ de 1986 y 1996 , respectivamente, a un $29,9 \%$ en 2013. Tanto en 1996 como en 2013, algo más de un $58 \%$ de las personas paradas tienen entre 35 y 44 años, frente a un $40 \%$ en 1986.

La principal implicación de esta tendencia ha sido el fuerte incremento del porcentaje de personas desempleadas con responsabilidades en el mantenimiento del hogar (persona principal del hogar o cónyuges) [Gráfico 15]. En 1996, apenas un $32,8 \%$ de las personas desempleadas tenían responsabilidades de hogar; en 2014, esa cifra llega al 63,1\%.

\section{Gráfico 13. Cambios en la tasa media de paro. Varias comunidades autónomas y España, 1992-1997 y 2009-2013 (\%)}

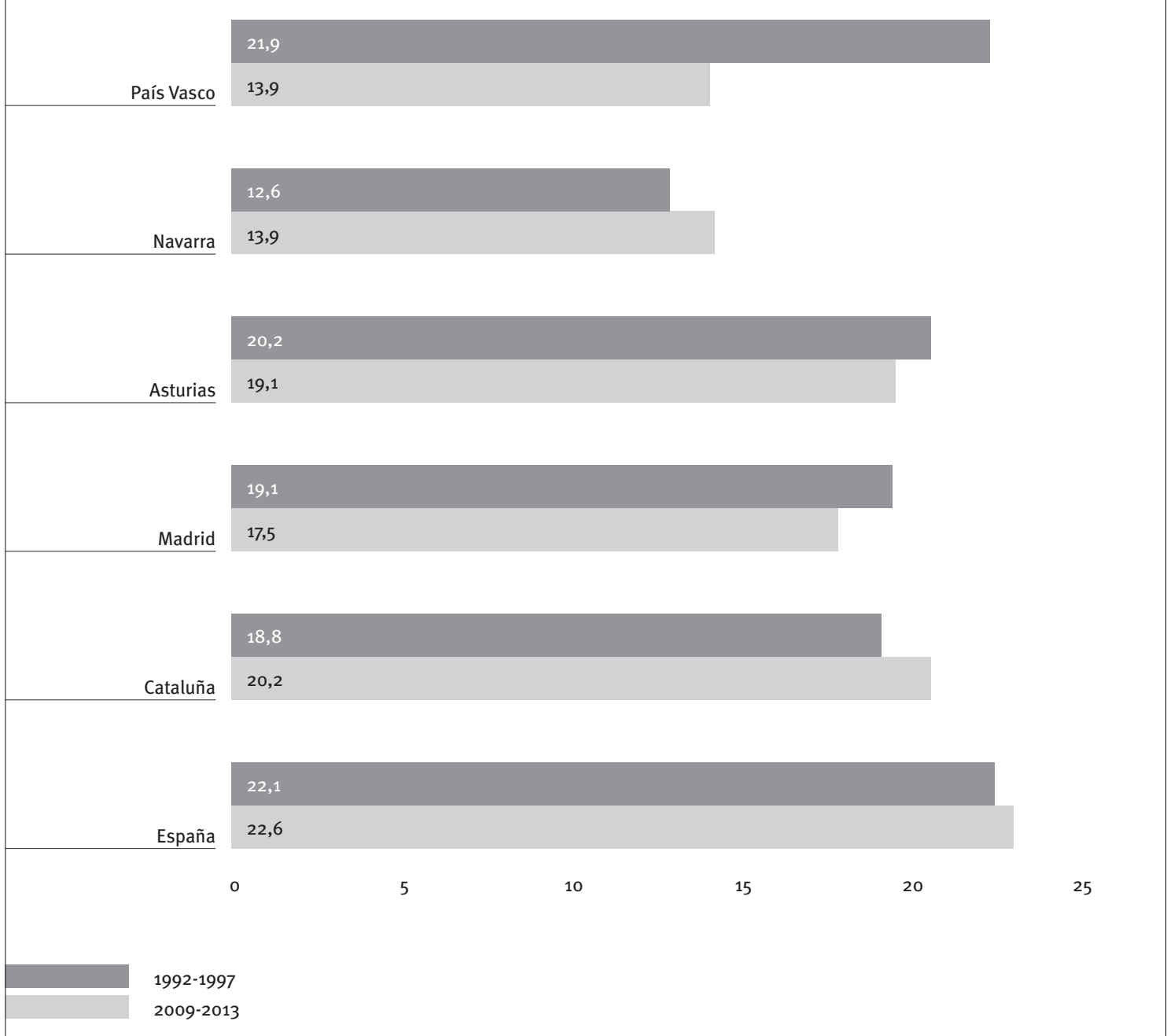

Fuente: Elaboración propia a partir de la Encuesta de la Población Activa (INE). 


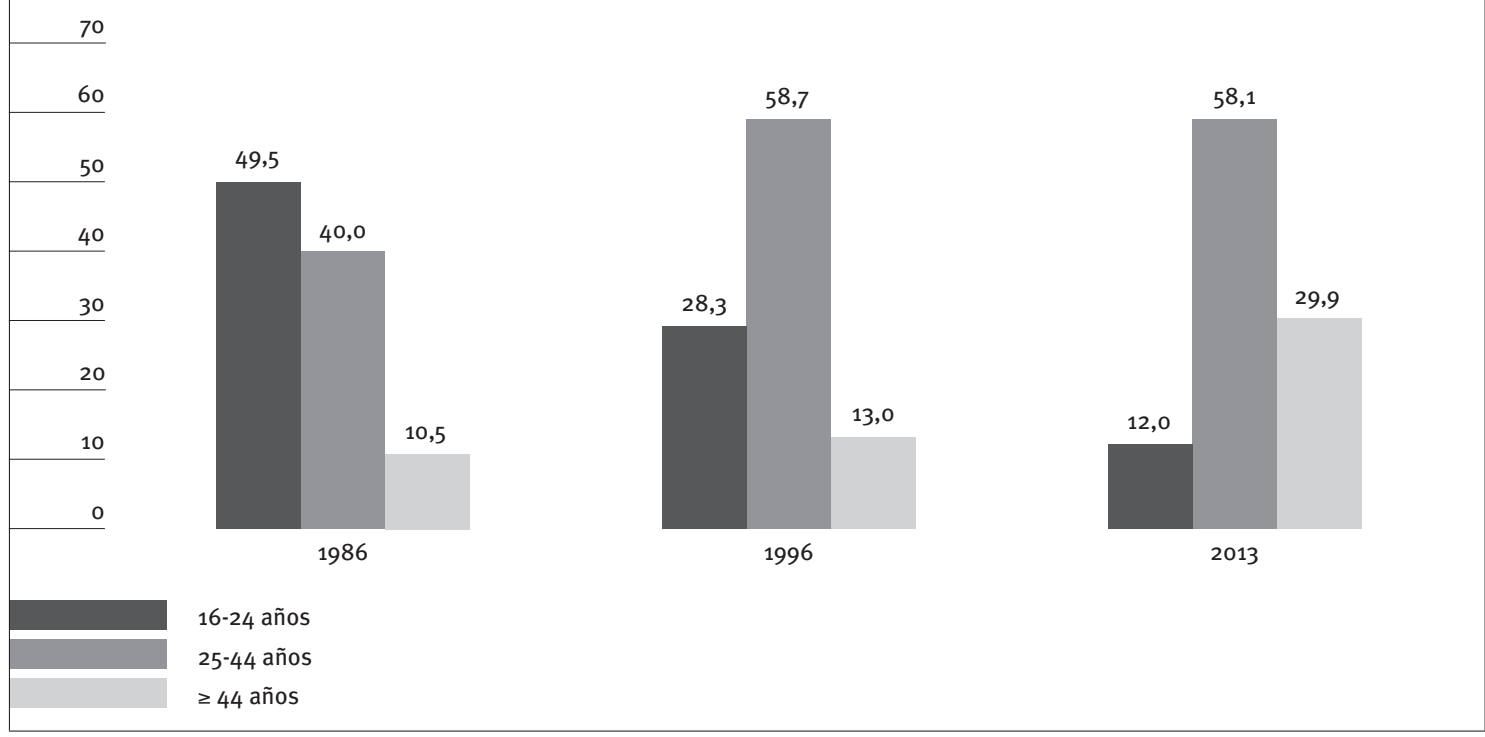

Fuente: Censo del Mercado de Trabajo (Órgano Estadístico del Departamento de Empleo y Políticas Sociales del Gobierno Vasco).

\section{Gráfico 15. Distribución de la población desempleada, por posición en el hogar. CAE, 1996-2014 (\%)}

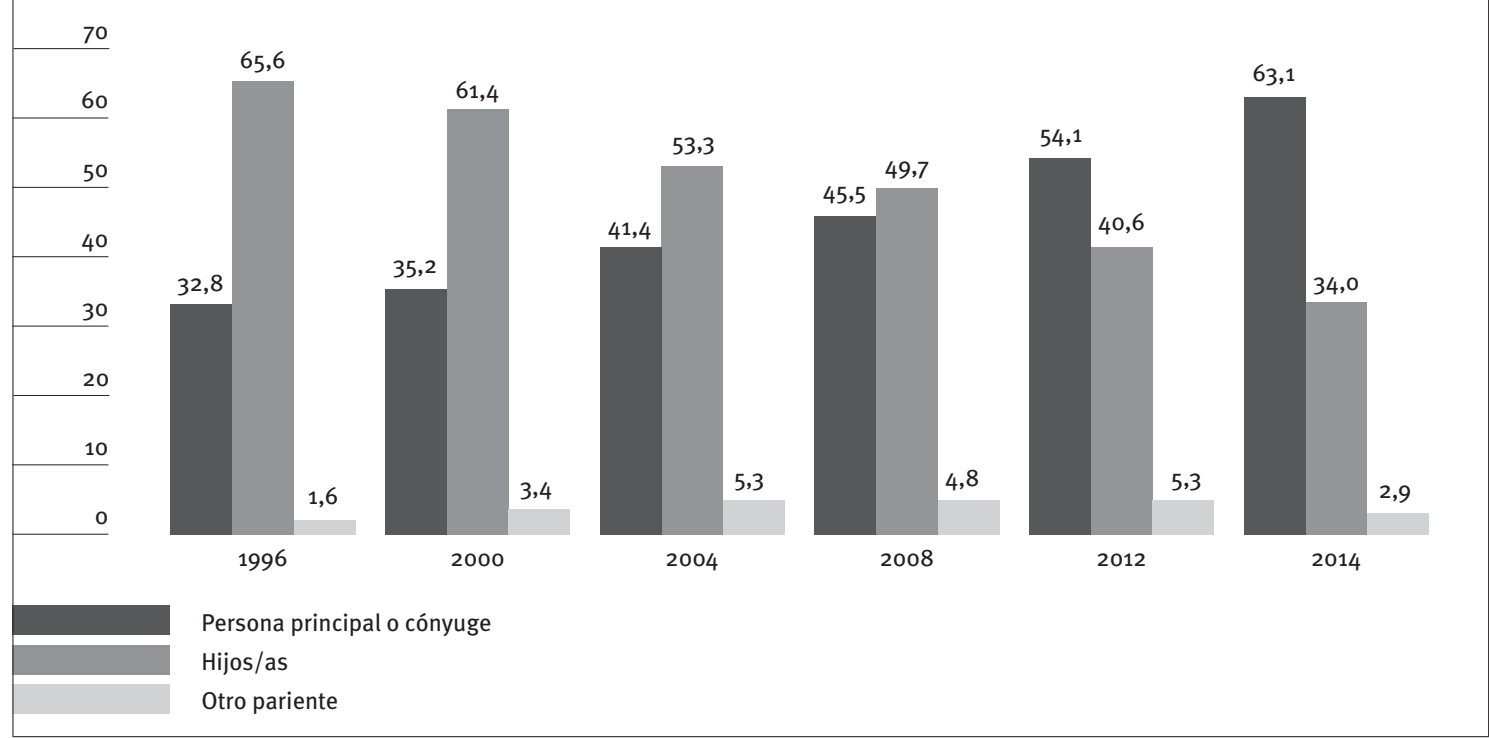

Fuente: Encuesta de Pobreza y Desigualdades Sociales (Órgano Estadístico del Departamento de Empleo y Políticas Sociales del Gobierno Vasco).

\subsection{La exclusión a largo plazo de una parte importante de la población parada del sistema productivo}

El segundo factor que acentúa el impacto social del desempleo es la exclusión a largo plazo del sistema productivo de una parte importante de la población parada. La Encuesta de Necesidades Sociales introduce en 1996 un nuevo indicador que trata de medir, desde una perspectiva social, el impacto de las situaciones de mayor cronificación en el desempleo. Este tipo de situaciones de exclusión estructural del sistema productivo incluyen a las personas que llevan 30 o más meses en desempleo y acceden a lo sumo ocasional- mente a trabajos marginales (más de 18 meses en el caso de las personas principales del hogar).

El dato más llamativo en este punto es que todavía en 2010 la crisis no se había traducido en Euskadi en un aumento llamativo de estos desempleados estructurales. Conformada por 30.380 personas en 2006 , la cifra apenas había avanzado a 34.813 en 2010. En 2014, sin embargo, se multiplica por tres, pasando a 114.147 (Gráfico 16). Este grupo de desempleados fuertemente alejados a largo plazo del sistema productivo resulta dominante en el desempleo actual en Euskadi, con los graves problemas sociales que conlleva. 


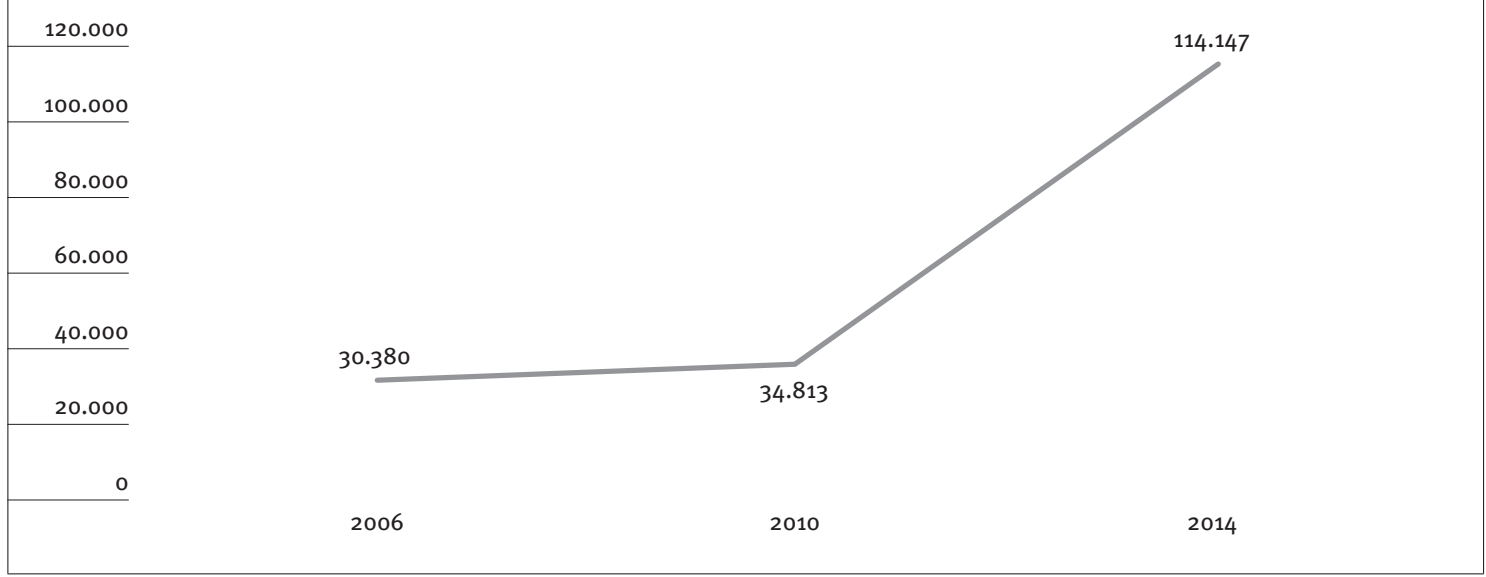

* Más de 30 meses en esa situación o más de 18 si se trata de la persona principal del hogar.

Fuente: Encuesta de Necesidades Sociales (Órgano Estadístico del Departamento de Empleo y Políticas Sociales del Gobierno Vasco, 2014 [avance]).

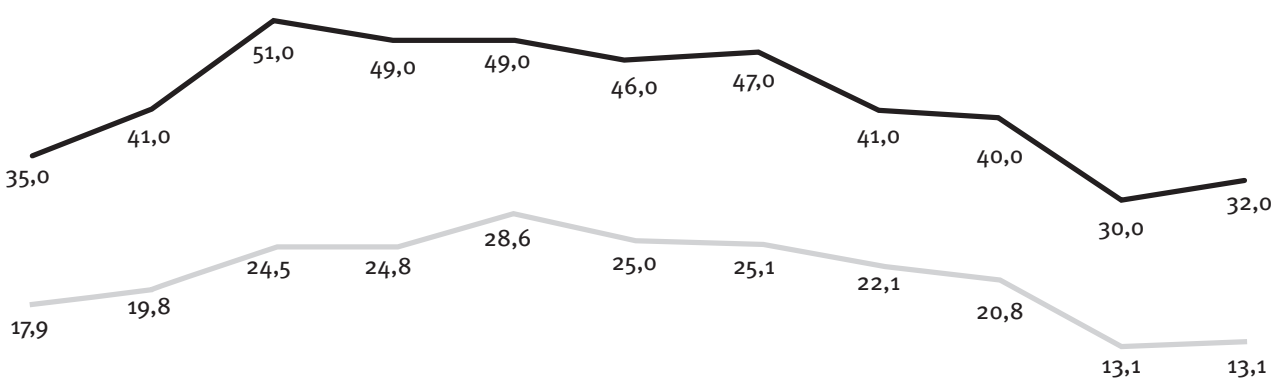

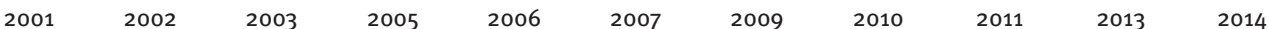

Experiencia de trabajo superior a seis meses

Experiencia de trabajo

Fuente: Censo del Mercado de Trabajo (Órgano Estadístico del Departamento de Empleo y Políticas Sociales del Gobierno Vasco).

El deterioro señalado se vincula a las crecientes dificultades, durante la crisis, para que la población parada acceda a un empleo. De esta forma, mientras que entre 2007 y 2009 alrededor del $46,5-47 \%$ de la población parada había conseguido trabajar durante algún momento de los últimos 12 meses, esa proporción no hace sino disminuir hasta 2013, cuando llega a un mínimo del 30,1\%. En la misma línea, mientras que un $28,6 \%$ de las personas desempleadas habían conseguido trabajar más de seis meses durante el último año en 2006, la proporción se reduce de manera progresiva a partir de entonces, hasta situarse en apenas un 13,1\% de la población parada en 2013 (Gráfico 17).

\subsection{La superación de la crisis social se retrasa respecto a la recuperación económica}

Los hechos señalados hasta ahora explican en gran medida por qué el comienzo de la recuperación económica no corre en paralelo con la superación de la crisis social. Al contrario, las consecuencias de la crisis en términos de formas más graves de desempleo tardarán todavía cierto tiempo en empezar a superarse y podrían agravarse en los próximos años.

Los datos del módulo EPDS 2014 revelan, de hecho, que la pobreza ha tendido al alza este $\mathbf{2 0 1 5}$, constatándose que aún no se ha iniciado el descenso de beneficiarios de la renta de garantía de ingresos. El motivo es que esta prestación hace frente a las fuertes limitaciones observadas en el sistema de protección estatal al desempleo, de modo que, en las circunstancias actuales, no se limita a completar los ingresos base garantizados por ese sistema, sino que constituye la principal alternativa a la desprotección de las personas en desempleo excluidas a largo plazo del sistema productivo. Éste constituye en la actualidad el núcleo de la pobreza real en Euskadi (Gráfico 18). 


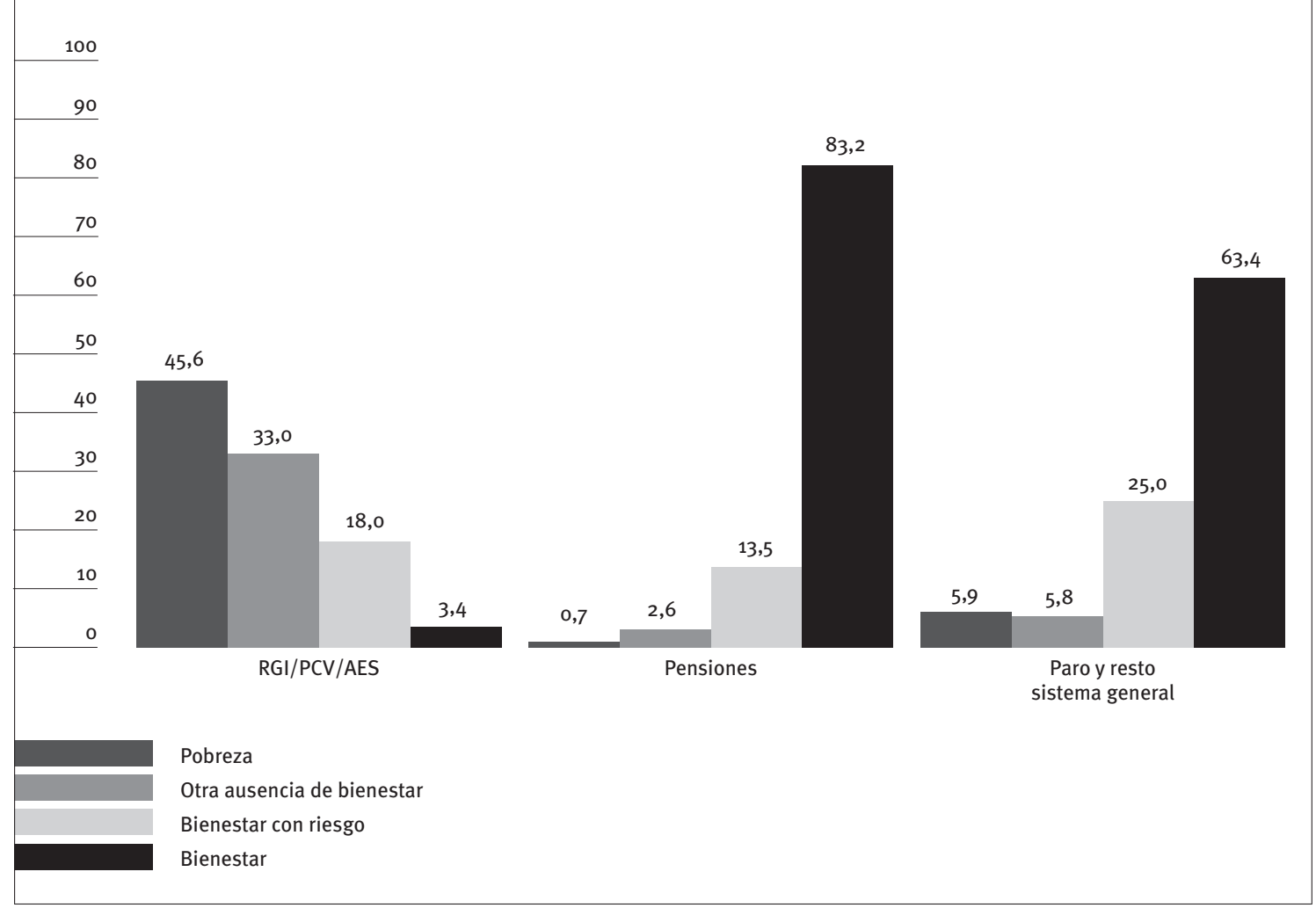

* Renta de garantía de ingresos (RGI), prestación complementaria de vivienda (PCV), ayudas de emergencia social (AES).

Fuente: Encuesta de Necesidades Sociales-Módulo EPDS (Órgano Estadístico del Departamento de Empleo y Políticas Sociales del Gobierno Vasco, 2014).

En este contexto de desprotección, la renta de garantía de ingresos (RGI) resulta necesaria para consolidar la cohesión social y prevenir las consecuencias más indeseadas de la crisis. Los recientes datos de la Encuesta de Condiciones de Vida (INE, 2014) muestran que las implicaciones sociales de esta política son positivas para la CAE: Euskadi es tanto la comunidad autónoma con menor tasa de pobreza como la que tiene los mayores ingresos personales medios. Lucha contra la pobreza y consolidación de un mayor bienestar de la población general se perfilan así como objetivos complementarios.

\section{La evolución del colectivo emprendedor y el papel del sector público}

Las situaciones descritas hasta ahora ponen de manifiesto la importancia de los retos pendientes. La crisis ha afectado, en este sentido, a grupos concretos de la población, situándolos de forma creciente y estructural al margen del sistema productivo. La crisis revela, por otra parte, las dificultades competitivas de la industria de los países más desarrollados de Occidente en el contexto de la globalización.

Uno de los retos es consolidar un volumen suficiente de población emprendedora. También en este punto la crisis ha tenido un impacto decisivo, con una caída del volumen de población autónoma o empresaria con asalariados/as de alrededor de 149.700 personas en 2005 a 134.800 en 2014 . Las cifras revelan, sin embargo, que el número de empresarios/as con trabajadores se ha mantenido relativamente estable durante la crisis, en general, además, en niveles superiores a los conocidos hasta 2005. En este aspecto, por tanto, la situación dista de ser negativa.

El mayor problema se refiere a la evolución de la población autónoma. En este caso, la crisis se ha traducido en un descenso de 112.400 autónomos/as en 2007 a 98.400 en 2014 (Gráfico 19). En este caso, la tendencia descendente era previa, con un máximo de 127.900 personas autónomas en 1997, iniciándose a partir de entonces la línea descendente hasta 2004 .

Parte del problema deriva del proceso de envejecimiento demográfico, con la jubilación de autónomos/as que no son sustituidos/as por la entrada en este ámbito de actividad de las nuevas generaciones. Evitar que este proceso negativo se acentúe en el futuro es un reto no menor para la supervivencia de un modelo económico vasco, que se sustenta, entre otros elementos, en una participación laboral importante de población autónoma. 


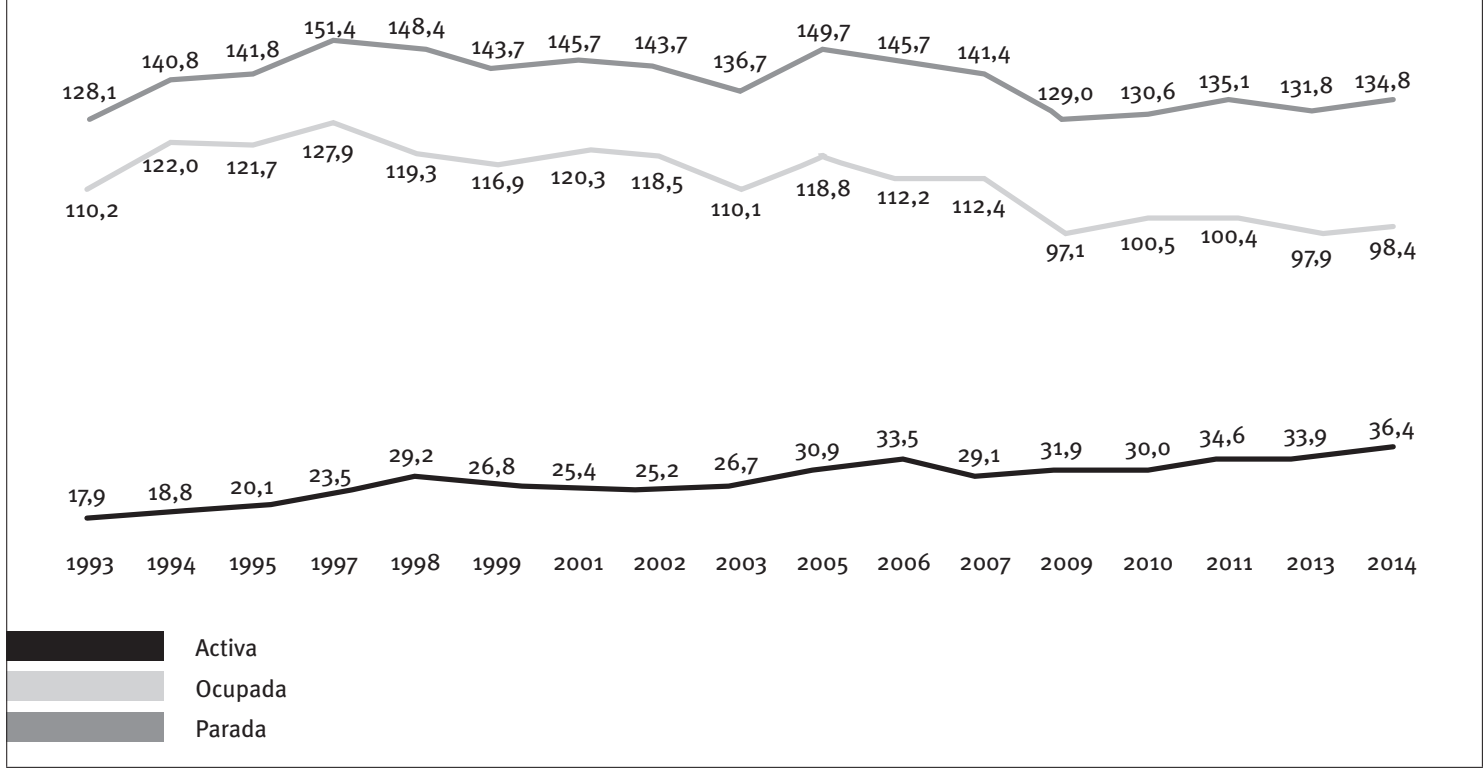

Fuente: Censo del Mercado de Trabajo (Órgano Estadístico del Departamento de Empleo y Políticas Sociales del Gobierno Vasco).

El otro factor clave para la sostenibilidad del modelo social y económico vasco es la capacidad del sector público para contribuir a una dinámica estable de la economía, lo mismo que a la creación de nuevas ocupaciones, en particular en el ámbito de los grandes servicios para la población (educación, sanidad, servicios sociales). En este punto, hay que señalar que, a pesar de la crisis y del importante esfuerzo que ha sido preciso realizar para mantener nuestro sistema complementario de protección social, las administraciones públicas vascas se presentan con una perspectiva financiera saneada ante el escenario de recuperación y con pérdidas ocupacionales significativas, pero comparativamente moderadas $(7,6 \%$ de la ocupación). Es de esperar que esto permita, conforme se vaya dejando atrás el escenario depresivo, recuperar el proceso de mejora en los servicios y la propia ocupación pública.

\section{Fuentes estadísticas utilizadas}

\section{ÓRGANO ESTADÍSTICO DEL DEPARTAMENTO DE EMPLEO Y POLIITICAS SOCIALES DEL GOBIERNO VASCO: Censo del Mercado de Trabajo.}

-: Encuesta de Condiciones de Trabajo.

-: Encuesta de Necesidades Sociales-Módulo EPDS.

EUROSTAT.

INSTITUTO NACIONAL DE ESTADÍSTICA (INE): Encuesta de Población Activa.

ORGANIZACIÓN PARA LA COOPERACIÓN Y EL DESARROLLO ECONÓMICO (OCDE).

OFFICE FOR NATIONAL STATISTICS: Labour Force Survey. 